\title{
ERRATUM
}

I. Rektor • I. Rektorová · M. Mikl • M. Brázdil

P. Krupa

\section{An event-related fMRI study of self-paced alphabetically ordered writing of single letters}

Published online: 28 April 2006

(C) Springer-Verlag 2006

\section{Exp Brain Res (2006) Dol 10.1007/s00221-006-0369-y}

Unfortunately, the complete last line in Table 1 (below "Alphabet versus dot, Right hemisphere" was deleted during the publication process.

The correct table is given here:

The online version of the original article can be found at http:// dx.doi.org/10.1007/s00221-006-0369-y

I. Rektor $(\varangle) \cdot$ I. Rektorová · M. Mikl · M. Brázdil

Department of Neurology, St. Anne's Hospital,

Masaryk University, Pekarska 53, 65691 Brno,

Czech Republic

E-mail: irektor@med.muni.cz

Tel.: +420-54-3182623

Fax: +420-54-3182624

P. Krupa

Diagnostic Imagining Clinic, St. Anne's Hospital,

Masaryk University, Pekarska 53, 65691 Brno,

Czech Republic 
Table 1 Localization of significant activated areas

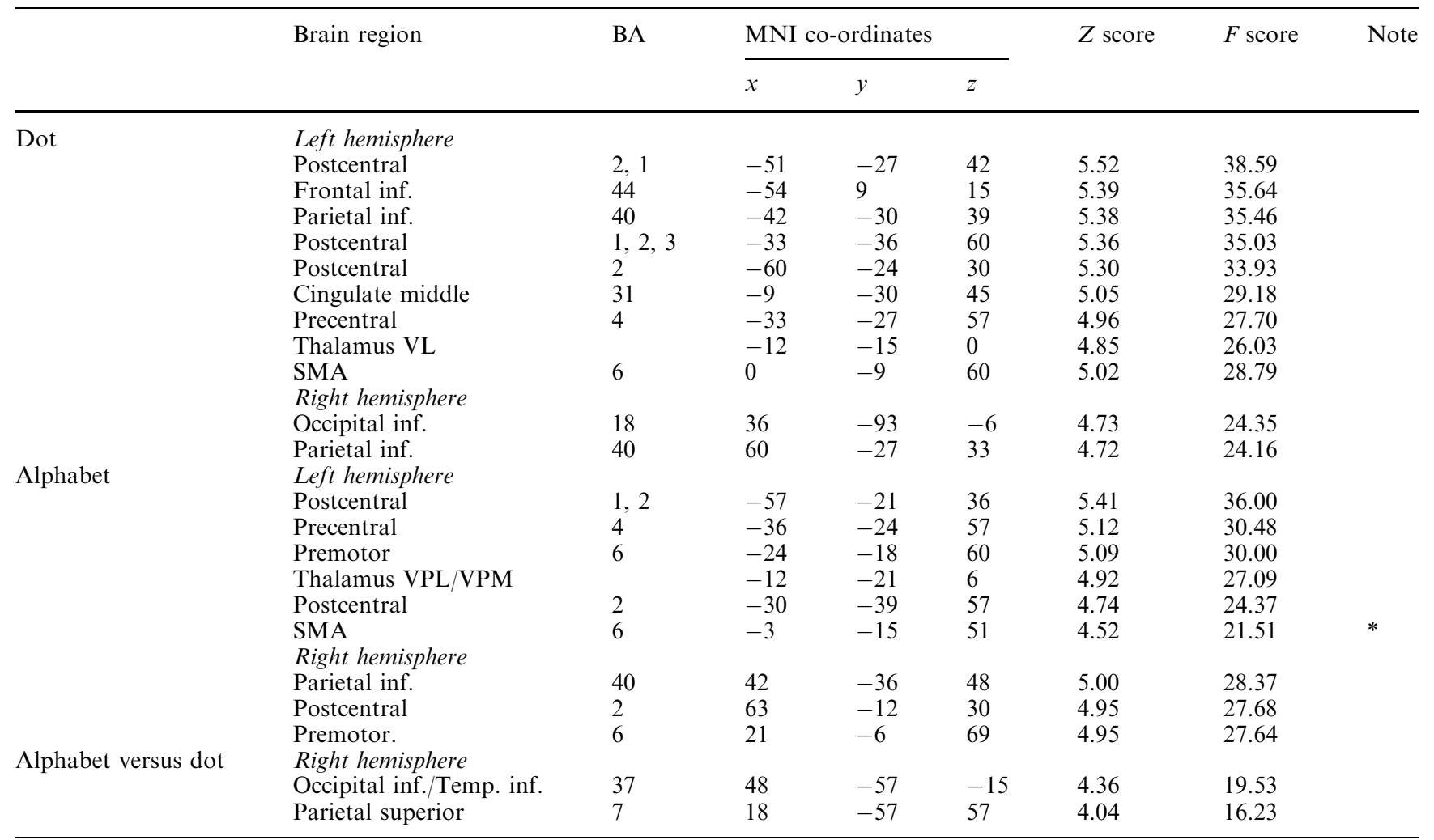

Standard $P=0.05$ corrected. *Denotes non-significant result with $P<3.0710^{-6}$ uncorrected. The comparison of Alphabet vs. Dot used an ROI analysis of the right-sided Brodmann areas (BA) 7 and 37, with a statistical threshold of $P<0.05$ corrected 